\title{
Gênero, trabalho e raça: um tripé insidioso de uma precarização histórica
}

\author{
Género, trabajo y raza: un trípode insidioso de una precariedad histórica
}

\begin{abstract}
Regina Lopes"
Olhem para mim? Olhem para meus braços! Eu arei e plantei, e juntei a colheita nos celeiros, e homem algum poderia estar à minha frente. $\mathrm{E}$ não sou uma mulher?' (Sojouner Truth, I85I)
\end{abstract}

Resumo: A proposta deste artigo é possibilitar uma reflexão sobre a subordinação da questão de gênero ao mundo "masculino" do trabalho. Evocar os pressupostos de um ideal de sociedade que alcançaria a modernidade através da industrialização - um território reconhecidamente masculino, que disseminou e intensificou as imagens sobre o trabalho feminino como algo "menor" e/ou negligenciada na produção do capital, nos permitirá o trânsito pelas fronteiras de uma desigualdade que não passou incólume ao longo da história às categorias coextensivas de gênero, raça e classe social na composição da divisão social (sexual) da vida humana. Resgatar e inferir sobre a presença das mulheres em suas especificidades neste processo de produção e reprodução do capital é fundamental para entendermos as metamorfoses do próprio capital como algo cíclico, sexista e racista.

Palavras-chave: Gênero; Trabalho; Raça

Resumen: La propuesta de este artículo es posibilitar una reflexión sobre la subordinación de la cuestión de género al mundo "masculino" del trabajo. Evocar los presupuestos de un ideal de sociedad que alcanzaría la modernidad a través de la industrialización -un territorio reconocidamente masculino-, que diseminó e intensificó las imágenes sobre el trabajo femenino

\footnotetext{
"Socióloga e doutoranda em Sociologia no Programa de Pós-Graduação em Sociologia da Universidade Federal de Sergipe/PPGS/UFS.

I Fragmento do discurso da Sojouner Truth na Women's Rights Convention em Akron, Ohio, Estados Unidos, em I85I.
} 
como algo "menor" y / o descuidado en la producción del capital, nos permitirá el tránsito por las fronteras de una desigualdad que no pasó incólume a lo largo de la historia a las categorías coextensivas de género, raza y clase social en la composición de la división social (sexual) de la vida humana. Resolver e inferir sobre la presencia de las mujeres en sus especificidades en este proceso de producción y reproducción del capital es fundamental para entender las metamorfosis del propio capital como algo cíclico, sexista y racista.

Palablas clave: Género; Trabajo; Raza

\section{Introdução}

Os pressupostos marxistas guiaram os estudos da sociologia do trabalho, assim como foram criadas divergências, tanto sobre o caráter da crise do capital, quanto da centralidade do trabalho na vida moderna. Surge, então, um confronto de ideias para explicar que o cenário das transformações dos meios de produção capitalista provocou o desmembramento da categoria trabalho, substituindo-a pelas inovações tecnológicas e outras esferas do fenômeno social; de outro lado, a defesa e a reafirmação da categoria trabalho não só como elemento de reajustamento do mercado, mas como condição de materialidade da vida dos trabalhadores/as. Porém, ambas as perspectivas negligenciaram o elemento feminino por tratá-lo como universal (masculino), reverberando nas demais categorias analíticas que invisibilizam a existência das mulheres como sujeito no curso da história, a exemplo da questão racial.

Em volta desta questão, Harvey (1992) salienta que mesmo com as transformações no mundo do trabalho, a inserção cada vez maior das mulheres no mercado não representou alteração significativa das suas condições de vida diante dos dispositivos morais (valores familiares, tradicional etc.) que aprisionaram suas perspectivas ao lar e a reprodução familiar. As definições dos papéis de gênero (feminino e masculino) são oriundas de uma sociedade patriarcal que influencia os tipos de acessos, ganhos e reconhecimento dentro da estrutura da produção e do mercado (BRUSCHINI, I998; SAFIOTI, I976; FEDERICI, 20I7).

$\mathrm{O}$ aumento da presença feminina no mercado de trabalho segue atrelado à divisão sexual, o que promove e justifica à precarização histórica da das condições laborais e diferenciação salarial, além da jornada reduzida que exige produtividade integral (ABRAMO, I998; HIRATA, 1998; NEVES, 2000; LEITE, 2004, PERROT, 2006), reforçando diferenças sexuais e de gênero racializadas (BAIRROS, 2000; CARNEIRO, 2002; 
GONZALEZ, I983 e 1994) dos lugares de homens e mulheres na cadeia produtiva do sistema capitalista.

Primeiramente, sob a pauta de gênero versus trabalho, objetivamos entender a dinâmica de diferenciação entre homens e mulheres nos seus acessos ao mercado de trabalho, a partir dos pressupostos de Karl Marx sobre o capital, e sua possível negligência ao trabalho não remunerado das mulheres nos meios de produção capitalista. A releitura crítica de Silvia Federici sobre "O Capital" e de Heleieth Saffioti, acerca da mulher na sociedade de classes, fornecerá elementos preciosos para apreendermos o processo de marginalização e inferiorização do feminino na produção-reprodução do capital.

No segundo momento, o debate de gênero cruzará trabalho e raça como categorias negligenciadas pelo próprio movimento das mulheres, brancas, diante da exclusão imposta aos corpos negros e as especificidades do movimento de mulheres negras, sinalizadas por três intelectuais que formaram uma legião no âmbito do feminismo negro: Lélia Gonzalez, Sueli Carneiro e Luiza Bairros. Mas, antes de avançarmos sobre esta questão, faz-se necessário apresentarmos o acirrado debate sobre as possíveis transformações nos cenários de crises do capital, à luz da sociologia do trabalho.

\section{O capital e suas metamorfoses: mobilidade, rigidez, flexibilidade e gênero}

O debate sobre flexibilização e precarização da força de trabalho vem suscitando inúmeros questionamentos sobre a centralidade do trabalho no processo de reestruturação produtiva, com novos padrões de gestão e desenvolvimento pautados em mais flexibilização tanto do emprego quanto do mercado, o que traz para às margens a questão de gênero nos espaços considerados masculinos (PEDROSA \& NEVES, 2007).

Para Druck (2002), a lógica hegemônica do capital financeiro se impõe a partir de três categorias elementares: mais mobilidade, menos rigidez e mais flexibilidade ${ }^{2}$. No entanto, a equação (mobi-rigi-flexi) aclamada nos dias atuais como saída de um cenário supostamente recessivo foi apresentada também como uma alternativa à crise do fordismo na década de I970 envolvida pelo discurso das novas exigências tecnológicas e econômicas do capitalismo moderno: desconcentração, flexibilização e redução de custos (BORGES \&DRUCK, 2002).

Esse mesmo dispositivo produziu um aumento exponencial de investimentos com a garantia em curto prazo e tendo por resultado a "crise do capital" de 2008, com efeitos

\footnotetext{
${ }^{2}$ Referência à equação: mais mobilidade, menos rigidez e mais flexibilidade.
} 
alarmantes em todo mundo, com aprofundamento das estruturas produtiva e salarial (CASTEL, 1998). Portanto, a marca da desfiliação social e da precarização da proteção social fazem parte do recorte das reformas trabalhista e previdenciária, como ocorre de forma recorrente no Brasil.

O quadro crítico que as crises do capital apresenta, sempre de forma cíclica como que organizada para promover e recriar novas demandas do mercado em suas interferências nos planos social, político e ideológico reverbera, sem dúvida, sobre àqueles/as que vivem do trabalho ou da "classe que vive do trabalho (ANTUNES, 2002).

(...) todos aqueles e aquelas que vendem sua força de trabalho em troca de salário, incorporando além do proletariado industrial, dos assalariados do setor de serviços, também o proletariado rural, que vende sua força de trabalho para o capital (...) os trabalhadores assalariados da chamada 'economia informal', que muitas vezes são indiretamente subordinados ao capital, além dos trabalhadores desempregados, expulsos do processo produtivo e do mercado de trabalho pela reestruturação do capital e eu hipertrofiam o exército industrial de reserva na fase de expansão do desemprego estrutural (ANTUNES, 2002, p. I03).

Antunes (2002) sinaliza a superficialidade da restruturação do capital por este não alterar a base da acumulação - exploração da classe trabalhadora, expondo o que define por acumulação flexível. O desemprego, a precarização das condições do trabalho e a devastação dos recursos naturais no âmbito global compõem a fase da estruturação produtiva. Neste sentido, a própria organização do mundo do trabalho lança sinais de que os seus princípios estão além do capital e solapa o seu principal protagonista - o trabalhador e em especial a vida das trabalhadoras por carregar em si características biológicas que são usadas para as múltiplas diferenciações entre o "trabalho masculino" e o "trabalho feminino". É justamente o debate de gênero que entrelaça a categoria trabalho para entendimento da dinâmica e das formas de participação da mulher no mercado de trabalho (DANIEL, 20II).

O capital que tem tão 'boas razões' para negar os sofrimentos da geração de trabalhadores que o circulam, não se deixa influenciar, em sua ação prática, pela perspectiva de degenerescência futura da humanidade e do irresistível despovoamento final (...). O capital não tem, por isso, a menor consideração com a saúde e com a vida do trabalhador, a não ser quando a sociedade o 
compele a respeitá-las (...) À queixa sobre degradação física e mental, a morte prematura, o suplício do trabalho levado até a completa exaustão, responde: 'Por que nos atormentarmos com esses sofrimentos, se aumentam nosso lucro? (MARX, I998, p. 3II)

Para Perrot (2006), a máquina entendida como um instrumento de disciplina, modelava tanto o espaço da fábrica quanto os corpos dos/as trabalhador/as, desagregando o capital do trabalho do/a operário/a. E, para Marx (1998), o processo de mecanização da produção possibilitou a inclusão de mulheres e crianças, mas também precarizou ainda mais a mão de obra masculina com o rebaixamento dos ganhos (salários) em virtude do incremento do exército de reserva industrial, ou seja, a massa emparedada, faminta e ansiosa para vender o suor do corpo como moeda para sobreviver por I4 horas no "asilo ideal de trabalho. Será mister transformar esse asilo em casa de terror" (MARX, 1998, p. 319).

No século XX, a intensificação no controle dos corpos (processo de trabalho) e maximização das operações (cronometragem rígida) fez surgir o modelo fordista/taylorista, mesclando os trabalhos manual e técnico. Ambos empregavam às máquinas para redução do tempo ocioso, aumento do ritmo do trabalho ${ }^{3}$ e separação de tarefas para execução (trabalhadores) e elaboração (especialistas). Mas na década de 1960, esse modelo cede lugar à uma "nova" configuração entre capital e trabalho - redução de posto de trabalhos, investimento em alta tecnologia e redirecionamento das fábricas para áreas mais pobres do planeta - mas também sobre o papel do Estado na manutenção das políticas públicas (ANTUNES, 2000a).

A informalidade ganha terreno e sua expansão alcança uma velocidade nunca vista com o avanço das tecnologias de informação na gestão das empresas capitalistas, promovendo um novo elemento de reestruturação do trabalho através do trabalho flexível, subcontratações e tempo parcial no trabalho, sem contudo significar melhores condições de trabalho, redução de trabalho e garantia de emprego, em especial para as mulheres que eram usadas em tarefas repetitivas e sem nenhuma garantia (HIRATA, 2007). Esse cenário transferiu as incertezas do mercado para o bolso dos/as trabalhadores/as, impondo novas e variadas formas de contratações (ANTUNES, 2000a; LIMA, 2006).

Da mesma forma que o cenário de terror imposto pelo binômio tecnologiaterceirização abarcou a materialidade e a subjetividade dos/as trabalhadores/as em tempos

3 Charles Chaplin faz referência ao modelo industrial no filme “Tempos Modernos”, uma obra prima. 
de incertezas, este lançou novos desafios para os/as estudiosos/as do mundo do trabalho. Surgiram então duas perspectivas: I. O trabalho deixaria de ser centralidade na compreensão dos fenômenos socais; 2 . O trabalho continua central na vida humana, porém multifacetado.

Na primeira perspectiva, encabeçada por Offe (1989) e Mèda (I999), o trabalho perde centralidade na construção da subjetividade humana, portanto se dilui o status de fato social, cedendo lugar para outras formas de organização social, além de um processo de "desencantamento do trabalho". Na segunda perspectiva, o trabalho não deixa de ser central na vida dos indivíduos, assim como as organizações de classe (trabalhadora) continuam a atuar de forma proeminente na representação e na defesa dos direitos dos/as trabalhadores/as na sociedade (ANTUNES 2000b, 2005, 2007; HIRATA, 2007; NEVES, 2000; LEITE, 2004; DRUCK, 2002). Compreende-se, assim, que a categoria trabalho, ao contrário de antes, se apresenta com múltiplos sentidos e requer uma visão também diferente sobre os fenômenos sociais, a exemplo dos trabalhos desenvolvidos pelas mulheres em suas múltiplas formas. Essa partícula de sentido construído pelo suor das mulheres foi negligenciado pela história (PERROT, 2006).

No século $\mathrm{XX}$, as mulheres operárias e esposas de operários já mantinham organizações femininas e reivindicavam direitos pelo duplo efeito do trabalho: donas de casa e gestoras do trabalho doméstico em prol de melhores condições de vida para as famílias; e o direito de ter o emprego. Não havia separação em suas defesas da valorização da família e da emergência do trabalho assalariado (THOMPSON, 200I). Porém, o maior dos embates era o reconhecimento do trabalho não remunerado ainda marginal nos debates até os dias atuais.

Se o modelo industrial sugava fisicamente a vida dos trabalhadores nas jornadas intermináveis da produção, levando-os ao limite de suas forças, há de se refletir sobre a participação das mulheres neste modelo ao acumular as jornadas de trabalho remunerado e não remunerado, acirrando ainda mais o fosso da divisão tradicional entre os sexos e instituindo a subordinação feminina (PERROT, 2006).

Para Hirata (2008) mesmo com a inserção das mulheres no mercado de trabalho, este movimento foi feito de forma precária em trabalhos flexíveis e sem prestígios. E, seguindo os pressupostos de uma concepção mais ampliada de trabalho diante dos cenários do avanço tecnológico e maior flexibilização, propõe uma reconceituação da categoria trabalho com o reconhecimento das categorias gênero e trabalho doméstico, ambos negligenciados dentro dos estudos do mundo do trabalho sob o viés do masculino. 
Nos estudos desenvolvidos por Lavinas (1997, 200I, 2006) foram analisados os períodos de 1970 a 1990 e o público preferencial das indústrias era: I. Mulheres solteiras e sem filhos, 2. Escolaridade mais elevada que a dos homens, 3. Ocupando os mesmos ramos de atividades dos homens no setor de serviços e indústria têxtil. As mulheres, mesmo após o casamento, seguiram suas buscas por trabalho remunerado e aceitavam ganhar salários menores pela empregabilidade. $\mathrm{O}$ fator escolaridade não modificou sua posição dentro da empresa no tocante à remuneração e nem ao prestígio de alçar outros postos com diferenças salariais acentuadas entre os sexos.

Abramo (1998), aponta que as mulheres, em virtude da discriminação de gênero eram incorporadas no mercado de trabalho através de contratações flexíveis e de subcontratação. Já Araújo (2012) explicita que estes tipos de inserção no mercado são permeados por muitas incertezas, insegurança e alta vulnerabilidade no toante à empregabilidade, o que tem levado às mulheres ao novo tipo de reestruturação produtiva organizadas em cooperativas no pós anos 1990 (NEVES, 2013).

No entanto, uma faceta deste cenário vivenciada pelas mulheres desde a industrialização, até os dias atuais, consta em relatórios descritos por Karl Marx em algumas passagens da sua obra clássica "O Capital". Os relatos, descritivos, seguidos de certo pavor, não foram suficientes para lançar uma problemática acerca do papel das mulheres na manutenção e reestruturação capitalista que não fosse realizado pelo movimento feminista anticapitalista e, em igual importância, por mulheres pesquisadoras acerca de um fenômeno alijado do todo das lutas trabalhistas. É a partir deste ponto que regressamos à obra "O Capital”, de Karl Marx, e ao clássico livro "A mulher na sociedade de classes" de Heleieth Saffioti, para melhor entender os desdobramentos quase que imponderáveis da presença feminina no mundo do trabalho.

Gênero, raça e trabalho doméstico (não remunerado): as alavancas invisíveis do capital?

Silvia Federici, professora emérita da Universidade Hofstra de Nova York, se debruça sobre as análises clássicas de Karl Marx na perspectiva de avaliar as ambiguidades das análises sobre gênero na obra "O Capital". Para ela, há limitações nessas análises na relação entre capitalismo, surgimento da industrialização e exploração do trabalho feminino e destaca: 
(I) a ausência de uma abordagem analítica, e não apenas meramente descritiva, da condição da mulher nas fábricas; (2) a omissão do papel do trabalho reprodutivo como um pilar do modo de produção capitalista; (3) a crítica à leitura de Marx que via no capitalismo um caminho necessário para criação das condições de emancipação da mulher (FEDERICI, 20I7, p. 83)

Nesta exposição, a autora não nega a importância crítica da obra, ao se contrapor a ideia de que apenas o trabalho industrial seria capaz de normatizar a atividade laboral através do capitalismo. Apenas retira da invisibilidade, afirmando, a determinação histórica também da relação binária "produtivo-reprodutivo" dos modos de produção capitalista do trabalho feminino.

Esse revisitar da obra "O Capital" renovou tanto o olhar quanto os consensos do marxismo e do feminismo acerca da categoria "gênero" e as hierarquias pelas quais as mulheres foram submetidas dentro de uma sociedade capitalista, escancarando as dissonâncias entre gênero e classe social, ao naturalizar e tornar periférico o trabalho doméstico (não remunerado) em contraposição ao trabalho industrial, sendo este último a chave para redução das desigualdades sociais.

Marx, apesar de sua condenação das relações patriarcais, nos deixou uma análise do capital e da classe a partir de uma perspectiva masculina - a do 'homem que trabalha', o assalariado industrial em cujo nome a Internacional se formou, considerado o portador da aspiração universal à libertação humana (FEDERICI, 20I7, p. 86).

O legado desta obra orientou toda uma geração de marxistas a dissociar as categorias gênero e raça do debate sobre classe social, mobilizando as feministas anticapitalistas e antirracistas, a partir da chave política do Marx, a problematizar e dar centralidade ao trabalho não remunerado e ao trabalho reprodutivo das mulheres.

A metade dos trabalhadores são meninos com menos de $\mathrm{I} 3$ anos $\mathrm{e}$ adolescentes com menos de I8. Essa indústria é tão insalubre, repugnante e mal-afamada que somente a parte mais miserável da classe operária, viúvas famintas etc., cede-lhes seus filhos, 'crianças esfarrapadas, subnutridas, sem nunca terem frequentado escola' (MARX, I998, p. 286) 
A análise descritiva da questão de gênero em Marx (1998), mesmo expondo toda brutalidade de um sistema que ceifou várias vidas, inclusive de mulheres e crianças, retratado nos capítulos “A jornada de trabalho" e "Maquinaria e grande indústria" não foram suficientes para mobilizar e visibilizar as pautas das mulheres em suas múltiplas determinações. Por ter um caráter descritivo, sua análise ficou restrita à participação das mulheres no trabalho fabril, desconsiderando sua subordinação às famílias burguesa e também operária, silenciando dilemas pertinentes à condição de ser mulher num mundo masculino e reduzindo o protagonismo feminino nas lutas por melhores condições de trabalho e das relações entre homens e mulheres na batuta dos costumes.

\footnotetext{
Elas tem tempo para aprender a cozinhar. Infelizmente, o tempo para dedicar-se às tarefas da cozinha coincidia com momentos em que não tinham o que comer [...] A crise a que nos referimos também era usada para ensinar as filhas trabalhadoras a costurar nas escolas. Foi necessário que uma revolução surgisse na América do Norte e que uma crise mundial fosse desencadeada para que algumas garotas trabalhadoras pudessem aprender a costurar, cujo trabalho consistia em fiar para o mundo inteiro (FEDERICI Apud Marx, 20I7, p. 98).
}

Nestes escritos, a alusão de que o avanço da maquinaria na sociedade industrial poderia dilui as diferenças de gênero e promover a emancipação humana disseminou a ideia de que a indústria com o avanço tecnológico suscitaria a libertação das mulheres do trabalho doméstico, a superação dos abusos sexuais, portanto do patriarcado. No entanto, o reconhecimento da condição da mulher no espaço fabril não possibilitou em igual medida centralidade às atividades reprodutivas domésticas como elementos dos modos de produção capitalista.

Assim, segue até os dias atuais a relação truncada entre trabalho e lar, gênero e trabalho. E a ilusão de que o capital dissolveria essa relação se apropriando do tempo útil da força de trabalho das mulheres também é aniquilada. Afinal, as metamorfoses do capital (consideradas crises) retroalimentam o imaginário social na distinção entre homens e mulheres e suas hierarquias cristalizadas de dentro do lar e todo tipo de uso da força laboral sob normas e controles também naturalizadas que depreciavam o trabalho doméstico, assim 
como Marx, diluindo a dicotômica relação entre produção-reprodução, precariza ainda mais o trabalho e a vida das mulheres e a recoloca no papel de reprodutora da principal chave de sustentação dos modos de produção capitalista - os trabalhadores ${ }^{4}$.

Descobrir a centralidade do trabalho reprodutivo para a acumulação de capital também levou à pergunta de qual seria a história do desenvolvimento do capitalismo se não fosse compreendida do ponto de vista da formação do proletariado assalariado, mas do ponto de vista das cozinhas e quartos onde a força de trabalho é produzida diariamente, geração após geração (FEDERICI, 20I7, p. I05)

A desvalorização do trabalho feminino é fruto da concepção de que cada ser humano (masculino) realiza a sim mesmo pelo trabalho (remunerado) com forte domínio sobre a natureza e a supervalorização da indústria e da tecnologia (digital) dos dias atuais. Há, portanto, um relação altamente significativa de desvalorização dos afazeres domésticos e da natureza (compreendidas no feminino), e submetidas pelo homem, compreendido como um ser universal.

Avançando, a partir da existência de uma divisão entre os sexos e da sua relação com as ocupações no mundo do trabalho, Heleieth Saffioti salienta que a marginalização das mulheres na estrutura ocupacional provém de um protótipo de equilíbrio mantido pelo sistema capitalista (BEZERRA, 20I3), em especial no tocante às diferenciações salariais pautadas nas também diferenciações biológicas.

O livro clássico "A mulher na sociedade de classes" de Saffioti (I976) visava compreender como a categoria sexo interferia na sociedade de classes ao ponto de desmerecer contundentemente à presença feminina no processo de produção-reprodução do capital. Para isso, faz uso do método dialético menos para realizar testes e mais para impulsionar, incorporando, uma crítica à própria estrutura analítica que alija de suas análises as categorias gênero e raça com a concepção de que estas serão superadas, mas que corroboram para manutenção da marginalização e inferiorização por parte de um sistema cada vez mais competitivo sobre a vida das mulheres.

\footnotetext{
${ }^{4}$ No masculino para reafirmar e refletir sobre o imaginário construído de negação do sujeito feminino na produção e reprodução do capital no tocante ao trabalho não remunerado.
} 
Saffioti (1976), já sinalizava a ambiguidade das análises acerca do trabalho que favorecia o sistema capitalista ao pautar suas narrativas no masculino e reivindicar para si a determinação sobre o lugar da mulher na sociedade de classe. Esse cenário provoca reações dos movimentos feministas que passam a intuir que "a classe operária tem dois sexos" (SOUZA-LOBO Apud BEZERRA, 2013, p. I72).

Os escritos de Saffioti (1976), uma mulher branca feminista, trouxe outro elemento para o entendimento acerca da acumulação do capital: o recorte racial. Para ela, o domínio do homem e branco sobre mulheres e negras é estruturado pela dinâmica capitalista que em suas metamorfoses configuram relações sociais desiguais. Assim, os fatores classe social, gênero e raça são dimensões estruturantes de uma realidade social desenvolvida a partir da discriminação, marginalização e inferiorização de determinados grupos sociais: mulher, pobre e negra, uma conexão compreendida a partir de uma relação interseccional (KERGOAT, 2OIO).

As ocupações das mulheres negras se diferenciam das ocupações das mulheres brancas, isso levando-se em consideração o recorte racial encoberto pelo mito da democracia racial à brasileira. Há sim restrições diferenciadas sofridas pelas mulheres - negras e nãonegras, no universo masculino de acesso compulsório ao mercado de trabalho.

No tocante ao lugar ainda não reconhecido das mulheres brancas no processo de produção e reprodução da acumulação do capital revela que sua inserção neste sistema foi duplamente desvantajosa: primeiro por acumular as tarefas ditas do lar e com os cuidadora com os filhos; segundo, por ainda ocupar, mesmo com maior escolaridade, postos inferiores aos homens com menor escolaridade, além dos consecutivos assédios sexual e moral em seus espaços de trabalho.

No tocante ao suposto acesso das mulheres negras às pautas da luta do feminismo ainda eurocêntrico, mesmo em terras brasis, o legado da Lélia Gonzalez nos dar o sentido real desta exclusão ao sintetizar o olhar sobre nós, mulheres negras, no imaginário ainda colonial da relação entre a produção do capital e os corpos negros: I. Empregada doméstica; 2. A mulata; 3. A mãe preta. Nos três tipos ela é vista na dimensão do corpo: I. O corpo forte para o trabalho: 2 . O corpo gostoso para saciar as necessidades sexuais; 3. $\mathrm{O}$ corpo que amamenta com o leite da mãe preta. Esta última secundariza o papel de mãe, por ser a outra (GONZALEZ, 1994). 
Luiza Bairros (2000), numa releitura de Lélia Gonzalez, sinaliza que as experiências de opressão que os corpos negros carregam são determinadas pelo campo que ocupamos na matriz de dominação que cruza raça, gênero e classe social. Neste sentido, não há hierarquia de opressões entre as mulheres negras e brancas e sim experiências impostas aos corpos negros que tombam no labirinto desigual, racista e sexista que modela a sociedade brasileira (GONZALEZ, 1983).

É dentro da perspectiva do feminismo negro que surge o olhar antirracista integrando as lutas do movimento de mulheres pelo direito às especificidades da existência e da reivindicação do "ser mulher" e negra numa sociedade que pauta no corpo a subalternidade compulsória, portanto passíveis às múltiplas violências. Mas, Sueli Carneiro (2002) também sinalizava a urgência dos movimentos de mulheres negras no sentido de enegrecer o feminismo em prol da reivindicação da cor para a construção de uma nova identidade política, capaz de combater as desigualdades de gênero e intergênero.

Neste sentido, o sistema de acumulação do capital se vale das estruturas de diferenciação moral, biológica e racial entre homens e mulheres e também entre as mulheres, forjadas no patriarcado, para reproduzi-las em todas as dimensões da vida e do mercado capitalista. Ao não reconhecer o trabalho não remunerado das mulheres na manutenção das famílias nos recortes de gênero e raça, tratando-as como objeto de reprodução de mais trabalhadores/as é, sem dúvida, precarizar ainda mais a vida das mulheres e em especial das mulheres negras já alijá-las da determinação histórica e da condição humana em suas múltiplas faces. Afinal, eu não sou mulher?

\section{À guisa de um continuum}

As perspectivas de gênero, apresentadas ao longo deste trabalho, salientam que nem a industrialização nem a tecnologia foram capazes de dar conta da materialidade da vida humana e, em especial, da existência das mulheres na produção-reprodução do mundo do capital, por reproduzirem relações dispares entre homens e mulheres, brancos e negros, pobres e ricos, a partir de uma equação repetidamente aplicada em tempos de "crises" e metamorfoses: mais mobilidade, menos rigidez e mais flexibilidade; portanto, mais precarização e servidão, prioritariamente aos corpos negros.

A lógica financeira, hegemônica, que se assenta sobre a equação "remota" do capital - mobilidade, rigidez e flexibilidade, portanto mais terceirização e menos participação do 
Estado - possui o quarto elemento, invisibilizado nas operações produtivas - o gênero e também a raça. E este dispositivo de controle, mas também do esquecimento, foi reproduzido apenas como um fator cultural, provocando acirramento no tocante à divisão entre os sexos e impõe subordinação ao feminino. Por outro lado, essas ambiguidades fortaleceram o discurso dos movimentos feministas que, a partir da obra "O Capital" de Karl Marx, refizeram um novo percurso sobre os relatos da participação das mulheres no processo de desenvolvimento da industrialização, além do ideário tecnológico para a quebra da dominação patriarcal.

Silvia Federici e Heleirth Saffioti, a partir da obra clássica "O Capital” de Karl Marx, revisitaram o método dialético para inferir sobre a condição das mulheres na sociedade capitalista, além de apontar distorções sobre as análises marxistas, muito mais descritivas do que críticas, que negligenciaram uma parte significativa da manutenção da acumulação do capital - o trabalho não remunerado realizado pelas mulheres e esposas dos operários. O direcionamento cristalizado das análises pautado no masculino não só favorece o capital quanto fortaleceu as redes de controle e dominação dos corpos femininos nas fábricas e nos lares, pauperizando ainda mais suas vidas e influindo para o acúmulo do capital.

A sinalização de que os dispositivos morais (familiares) sobre os corpos femininos eram reproduzidos tanto na esfera burguesa quanto na esfera operária, influenciou fortemente os acessos e os alcances de homens e mulheres em suas ocupações laborais. Por outro lado, fortaleceu outra demanda por garantia de direitos das mulheres que proclamava a existência de dois sexos na luta operária.

O fortalecimento da pauta dos direitos das mulheres no mercado de trabalho não lhe garantiu nem libertação nem reconhecimento, mas acúmulo de atividades consideradas menores e inferiores aos homens - o mundo do lar e da reprodução. Neste sentido, o processo de apagamento das mulheres do ambiente laboral, externo ao lar, foi forjada na concepção de que tudo que estivesse envolvido pelo feminino - afazeres e cuidados domésticos, a natureza etc., - existiria apenas sobre o domínio do masculino - o ser universal.

O debate sobre flexibilização e precarização da força de trabalho ainda negligencia um contingente considerável para manutenção dos meios de produção capitalista - as mulheres e o trabalho não remunerado. O processo de reestruturação produtiva que tanto impacta a vida dos homens também solapa a vida das mulheres que passam a ocupar funções menores, com salários menores para manter a empregabilidade, mesmo com mais anos de 
estudos do que os homens. Essa lógica aplica-se à demanda defendida pela mulher branca, o que não corresponde às demandas das mulheres negras subalternizadas duplamente: primeiro em relação ao ser universal - masculino; segundo em relação à negligência do movimento feminista de formação eurocêntrica que não reconhece a história de luta das mulheres negras e suas especificidades no tocante ao processo de subalternidade imposta pelo capital ao mundo pré-determinado do trabalho doméstico restrito aos corpos negros (BAIRROS, 2000; CARNEIRO, 2002, GONZAGALES, 1983 e I994).

A reivindicação do feminino, do gênero, não como divisão, mas como parte do processo histórico, portanto sujeito da história social, política e econômica que, assim como os homens, tem suas vidas postas em condições terríveis de existência, ainda vivem suplantadas pelo sistema capitalista que se vale dos valores tradicionais da divisão social (sexual) da vida para impor o seu padrão distintivo e usurpador daquelas que se juntam cotidianamente aos reais deserdados da terra - a classe trabalhadora, negra, que vive e existe em prol do trabalho. Afinal, negligenciar outras categorias de análise, portanto de existência como raça, faz parte do processo cíclico e engenhoso do capital, um elemento que tende a universalizar tudo ao redor e, consequentemente, fragmentar as lutas.

\section{Referências Bibliográficas}

ABRAMO, Laís. Um olhar de gênero: visibilizando precarizações ao longo das cadeias produtivas. In: ABRAMO, Laís; ABREU, Alice de Paiva (Orgs.). Gênero e trabalho na sociologia latino-americana. São Paulo: Alast, I998. p. 39-6I.

ANTUNES, Ricardo. O privilégio da servidão: o novo proletariado de serviços na era digital. I.ed. São Paulo: Boitempo, 2018.

. Dimensões da precarização estrutural do trabalho. In DRUCK, Graça; FRANCO, Tânia (orgs). A perda social da razão do trabalho: terceirização e precarização. São Paulo: Boitempo, 2007.

. O caracol e sua concha: ensaios sobre a nova morfologia do trabalho; Ed. Boitempo: São Paulo, 2005.

Anotações sobre o capitalismo recente e a reestruturação produtiva no Brasil. In ANTUNES, Ricardo; SILVA, Maria M. (orgs). O avesso do trabalho. São Paulo: Expressão Popular, 2004. 
. Os Sentidos do trabalho: ensaio sobre a afirmação e a negação do trabalho. São Paulo: Boitempo, 2000a.

Adeus ao trabalho? Ensaio sobre as metamorfoses e a centralidade do mundo do

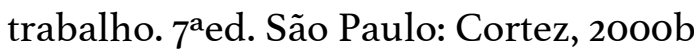

BAIRROS, Luiza. Lembrando Lélia Gonzalez. In: WERNECK, Jurema; MENDONÇA, Maísa e WHITE, Evelyn C.O livro da saúde das mulheres negras - nossos passos vêm de longe. Rio de Janeiro, Criola/Pallas, 2000. Disponível em: http://www.afroasia.ufba.br/pdf/afroasia_n23_p347.pdf.

BEZERRA, Eliane. A originalidade do pensamento de Heleieth Saffioti na análise crítica sobre a condição da mulher na sociedade capitalista. Lutas Sociais, São Paulo, vol.I7 n.3I, p.I70-I73, jul./dez. 2013.

BORGES, Ângela; DRUCK, Graça. Terceirização: balanço de uma década. Caderno CRH, Salvador, n. 37, p. III-I39, jul./dez. 2002.

BRUSCHINI, Cristina. Trabalho doméstico: inatividade econômica ou trabalho não remunerado? In ARAÚJO, C.; PICANÇO, F.; SCALON, C. (orgs.). Novas conciliações e antigas tensões? gênero, família e trabalho em perspectiva comparada. BAURU, SP: EDUSC, 2007.

CARNEIRO, Sueli. Mulheres em movimento. Estud. av. [online]. 2003, vol.I7, n.49 [cited 20I4-08-3I], pp. II7-I33.

CASTEL, Robert. As metamorfoses da questão social: uma crônica do salário. Petrópolis: Vozes, 1998.

DANIEL, Camila. O trabalho e a questão de gênero: a participação de mulheres na dinâmica do trabalho. O Social em Questão - Ano XIV - no 25/26 - 20II, p 323-344.

DRUCK, Graça. Flexibilização e precarização: formas contemporâneas de dominação do trabalho. Caderno CRH, Salvador, n. 37, p. II-22, jul./dez, 2002.

FEDERICI, Silvia. Notas sobre gênero em o Capital de Marx. Tradução de Giovanna Henrique Marcelino. Cadernos Cemarx, 2017, 83-108p.

GONZALES, Lélia. Lélia fala de Lélia. Revista Estudos Feministas, n.2, 2º semestre de 1994, p. 383-286. Disponível em: http://www.ieg.ufsc.br/admin/downloads/artigos/30102009034559lelia.pdf.

. Mulher Negra. In: Revista Afrodiáspora. A.3, n 6-7, São Paulo: IPEAFRO, 1985. 
. Racismo e sexismo na cultura brasileira. In: SILVA, Luís Augusto. ANPOCS, 1983. (Ciências Sociais Hoje, $\mathrm{n}^{\circ}$ 2).

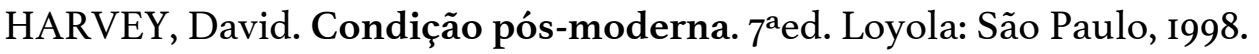

HIRATA, Helena. Visão comparativa sobre o trabalho feminino na França, Japão e no Brasil. In LIMA, M. E. et al (orgs.) Transformando as relações trabalho e cidadania: produção, reprodução e sexualidade. São Paulo: CUT/BR, 2007.

HIRATA, Helena; KERGOAT, Danièle. Novas configurações da divisão sexual do trabalho. Cadernos de Pesquisa, v. 37, n. I32, p. 595-609, 2007.

. Reestruturação produtiva, trabalho e relações de gênero. Revista Latinoamericana de Estudios del Trabajo. Ano 4. n.7. São Paulo, ALAST, 1998.

LAVINAS, Lena. NICOL, Marcelo. Atividade e vulnerabilidade: quais os arranjos familiares em risco? Revista de Ciências Sociais, Rio de Janeiro, v. 49, n. I, 2006.

. Empregabilidade no Brasil: inflexões de gênero e diferenciais femininos. IPEA. Rio de Janeiro, $200 I$.

Emprego feminino: O que há de novo e o que se repete. Dados. Rio de Janeiro. v. 4O, nº I, 1997. LEITE, Miriam M. A condição feminina no Rio de Janeiro: século XIX: antologia de textos de viajantes estrangeiros. São Paulo: Edusp/Hucitec, 1993.

MARX, Karl. O Capital - Crítica da economia política. Livro Primeiro. O processo de Produção do Capital. Tradução de Reginaldo Sant'Anna. v.I. I6. ed. Rio de Janeiro: Civilização, 1998.

MÈDA, Dominique. Trabalho: um valor em via de extinção. Lisboa: Fim do século, $200 I$.

NEVES, Magda de Almeida. Anotações sobre o trabalho e gênero. Cadernos de Pesquisa, v. 43 n. I49, p. 404-42I, maio/ago. 2013.

NEVES, Magda de Almeida; PEDROSA, Célia Maria. Gênero, flexibilidade e precarização: o trabalho a domicílio na indústria de confecções. Soc. estado., Brasília, v. 22, n. I, p. II-34, 2007. OFFE, Claus. Trabalho como categoria sociológica fundamental? In OFFE, C. (org.) Trabalho e sociedade: problemas estruturais e perspectivas para o futuro da "sociedade do trabalho". Rio de Janeiro: Tempo Brasileiro, 1989.

PERROT, Michele. Os excluídos da história. São Paulo: Paz e Terra, 2006.

KERGOAT, Danièle (20I0) Dinâmica e consubstancialidade das relações sociais. Novos Estudos Cebrap, São Paulo, n.86, pp.93-I03.

SAFFIOTI, Heleieth. A Mulher na Sociedade de Classes: mito e realidade. Petrópolis/RJ: Vozes, 1976, 384p 
SOUZA-LOBO. Elizabeth (20II). A classe operária tem dois sexos: trabalho, dominação e resistência. São Paulo: Perseu Abramo. $2^{\mathrm{a}}$ edição.

THOMPSON, Eric Palmer. A formação da classe operária inglesa. 3 v. Rio de Janeiro: Paz e Terra, 200I.

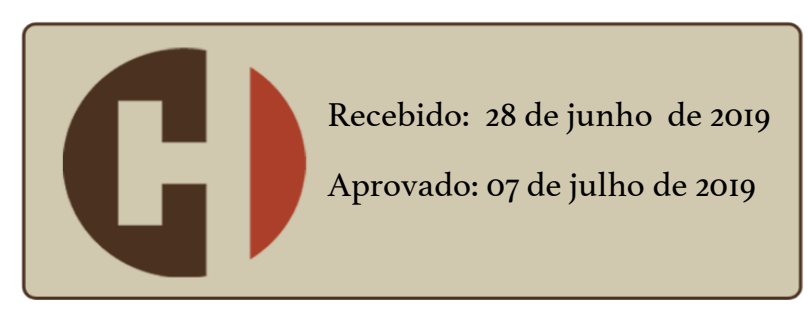

